East African Medical Journal Vol. 80 No. 10 October 2003

GEOMETRIC MEASUREMENTS OF THE ACETABULUM IN ADULT MALAWIANS: RADIOGRAPHIC STUDY

B. C. Msamati, MD, PhD, Professor, P. S. Igbigbi, Professor, MBBS, MSc, Department of Anatomy and C. B. D. Lavy, BSc, MBBS, MCh, FRCS, Department

of Surgery, College of Medicine, University of Malawi, Private Bag 360, Blantyre 3, Malawi

Request for reprints to: Prof. B. C. Msamati, Department of Anatomy, College of Medicine, Private Bag 360, Blantyre 3, Malawi

\title{
GEOMETRIC MEASUREMENTS OF THE ACETABULUM IN ADULT MALAWIANS: RADIOGRAPHIC STUDY
}

\author{
B. C. MSAMATI, P. S. IGBIGBI and C. B. D. LAVY
}

\begin{abstract}
Objectives: To determine the acetabular depth as well as acetabular and centre edge angles; to assess the influence of sex, if any, in these geometric measurements; and to determine the prevalence of hip dysplasia in adult Malawians.

Design: A retrospective study.

Setting: Queen Elizabeth Central Hospital (QECH) and Blantyre Adventist Hospital (BAH).

Main outcome measures: The acetabular and centre edge angles, acetabular depth and the prevalence of hip dysplasia were determined.

Materials and methods: Two hundred and fifty three bilateral radiographs of the hip from adults, 133 men and 129 women, were used to measure the acetabular depth, angle and centre edge angle using a calliper and goniometer. The radiographs were taken from patients with no underlying bone disease between January 1997 and February 2001 at QECH and BAH.

Results: The prevalence of hip dysplasia was $11.54 \%$ for men and $13.16 \%$ for women with respect to centre edge angles but this difference by sex was not significant $(\mathbf{P}>0.1)$. However, the prevalence of hip dysplasia with respect to centre edge angle showed significantly more dysplasia in Malawian men than Nigerian and Chinese men $(P<0.001$ and $\mathbf{P}<0.05$, respectively). Centre edge angles also showed a wider range in Malawian men $\left(19-51^{\circ}\right.$ right, and $15-52^{\circ}$ left $)$ than women $\left(18-45^{\circ}\right.$ right, $20-46^{\circ}$ left $)$. In both hips, the acetabular angles were more obtuse in men $\left(35.52^{\circ}\right.$ right, $34.21^{\circ}$ left $)$ than women $\left(29.43^{\circ}\right.$ right, $29.29^{\circ}$ left $)$, and this difference was significant $(P<0.001)$. The ranges of acetabular angles were wider in women $\left(11-38^{\circ}\right.$ right, $8-40^{\circ}$ left $)$ than men $\left(24-49^{\circ}\right.$ right, $20-40^{\circ}$ left $)$. Acetabular depth was also greater in men than in women $(\mathrm{P}<0.01$ right hip, $\mathrm{P}<0.02$ left hip).

Conclusion: Sex influences geometrical measurements of the acetabulum. The prevalence of hip dysplasia with respect to centre edge angle was significantly higher in women than men and the prevalence for men with respect to centre edge angle was significantly different when compared with Nigerian and Chinese men. This information will assist clinicians in the region and Malawi in particular to interpret hip X-rays of African patients.
\end{abstract}

\section{INTRODUCTION}

The acetabulum is a cup-shaped socket of the hipbone that derives its name from its resemblance to a shallow Roman vinegar cup (1). In clinical medicine, measurements of the acetabulum are crucial in diagnosis, monitoring patient recovery, determining stability of the hip joint and in assessment of acetabular dysplasia (2). The decision for operative treatment is often based on different radiographic measurements and scores for which normal values are defined (3). Therefore orthopaedic surgeons often use combinations of measurements when assessing acetabular parameter. McCarthy and colleagues (3), for example, emphasised the importance of these measurements during their study on innominate osteotomy in adolescents and adults who had acetabular dysplasia. During their study, acetabular and centre-edge angles amongst other parameters were used to evaluate Salter innominate osteotomy and assess patient recovery after operation. In another study Ali-Gombe and colleagues (4) reported on osteoarthritis of the hip and acetabular dysplasia in Nigerian men. Such observations were only possible by using geometrical measurements of acetabular, and clearly radiographic findings helped to determine the natural history of residual dysplasia (4).

A number of authors have also shown that geometrical measurements of acetabular differ with 
respect to age, sex, and race $(5,6)$ and even within regions (7). There is paucity, however, of hip measurements in East and Central Africa and Malawi in particular, in spite of the crucial role they play in clinical medicine. Acetabular measurements were therefore made from X-ray films at QECH and BAH, the two large hospitals in Blantyre city, in order to establish baseline data and determine the prevalence of hip dysplasia in adult Malawians.

\section{MATERIALS AND METHODS}

A total of 280 antero-posterior bilateral radiographs were collected from the archives at QECH and BAH from January 1997 to February 2001. Of these, 36 radiographs were excluded: nine with fractures of the hip, eleven had no clear acetabular boundaries, six were not in focus and ten were of children.

Two hundred and fifty three bilateral radiographs of the hip from 133 male and 120 female adult subjects were studied by measuring the acetabular depth, angle and centre edge angle using a calliper and goniometer. The criteria for choosing pelvic radiographs taken in neutral position (8) included: intact pelvis and hip joint, intact Shenton's line, intact cortices at the femoral heads, no history of fractures at femoral necks and no hip or pelvic bone disease. All films were taken at the object-film distance of $5 \mathrm{~cm}$ and focalfilm distance of $92 \mathrm{~cm}$ in the antero-posterior view, and a magnification correction factor of $2.86 \%$ was applied (9). The case notes showed that all patients were indigenous Malawians.

Acetabular Depth $(A D)$ : The acetabular depth is the length measured along a perpendicular line after joining the superior and inferior lips of the acetabulum (XY) from the midpoint of the lips to the deepest point of the acetabulum (Figure 1).

Acetabular Angle (AA): The acetabular angle is formed between the intersection of a line joining the superior triradiata cartilage of both sides of the pelvis (PQ), a perpendicular line at the superior lip of acetabulum and the line joining the superior and inferior margins of the acetabulum (XY), (Figure 1).

Centre Edge Angle (CEA): The centre edge angle is formed by the intersection between a perpendicular line passing through the centre of the femoral head and the line joining the centre of the femoral head to the superior lateral part of the acetabulum (Figure 1).

A goniometer was used to measure the acetabular and centre edge angles, while a calliper (Novel Products Inc. Pat. No 4.233.743) was used to measure acetabular depth. Dysplasia was defined as centre edge angle of less than $25^{\circ}$ or acetabular depth of less than $9 \mathrm{~mm}$ (10). Two trained students made three measurements independently; if differences of more than $1 \mathrm{~mm}$ and $1^{\circ}$ occurred on any radiograph, the measurements were repeated until the two observers came closer. The measurements were recorded separately for each sex and side of the hip and t-tests were used for statistical analysis, as these measurements were non-discrete.

\section{RESULTS}

The prevalence of hip dysplasia with respect to centre edge angle was $11.54 \%$ men and $13.16 \%$ women, but the difference was not significant $(\mathrm{P}>0.1)$
(Table 4). The mean centre edge angles showed a wider range in men than in women, but the difference was not statistically significant $(\mathrm{P}>0.5)$, (Table 1). Acetabular angles were more obtuse in men for both hips than women but the ranges were wider in women than in men.

Table 1

Centre-edge angles in adult Malawians

\begin{tabular}{|c|c|c|c|c|}
\hline & \multicolumn{2}{|c|}{ Males $(n=133)$} & \multicolumn{2}{|c|}{ Females $(n=120)$} \\
\hline & Right & Left & Right & Left \\
\hline Mean & $34.82^{\circ}$ & $33.32^{\circ}$ & $33.51^{\circ}$ & $35.31^{\circ}$ \\
\hline SD & 4.56 & 4.73 & 4.51 & 3.92 \\
\hline Range & $19-51^{\circ}$ & $16-52^{\circ}$ & $18-45^{\circ}$ & $20-46^{\circ}$ \\
\hline $\mathrm{P}$ & \multicolumn{2}{|c|}{$\mathrm{ns}$} & \multicolumn{2}{|c|}{ ns } \\
\hline
\end{tabular}

$\mathrm{ns}=$ not significant

Table 2

Acetabular angles in adult Malawians

\begin{tabular}{|c|c|c|c|c|}
\hline & \multicolumn{2}{|c|}{ Males $(n=133)$} & \multicolumn{2}{|c|}{ Females $(n=120)$} \\
\hline & Right & Left & Right & Left \\
\hline Mean & $35.52^{\circ}$ & $34.21^{\circ}$ & $29.43^{\circ}$ & $29.29^{\circ}$ \\
\hline SD & 3.27 & 3.99 & 2.19 & 4.22 \\
\hline Range & $24-49^{\circ}$ & $20-40^{\circ}$ & $11-38^{\circ}$ & $8-40^{\circ}$ \\
\hline $\mathrm{P}$ & \multicolumn{2}{|c|}{ ns } & \multicolumn{2}{|c|}{ ns } \\
\hline
\end{tabular}

$\mathrm{ns}=$ not significant with respect to side, but acetabular angles were significantly different $(\mathrm{P}<0.001)$ both hips with respect to sex.

Table 3

Acetabular depths ( $\mathrm{mm}$ ) of pelvis of adult Malawians

\begin{tabular}{lllll}
\hline & \multicolumn{2}{c}{ Males $(\mathrm{n}=52)$} & \multicolumn{2}{c}{ Females $(\mathrm{n}=38)$} \\
& Right & Left & Right & Left \\
\hline Mean & 31.7 & 31.8 & 29.5 & 29.8 \\
SD & 1.55 & 1.86 & 2.06 & 2.12 \\
Range & $12.0-32.0$ & $15.0-33.0$ & $23.0-38.0$ & $24.0-39.0$ \\
P & \multicolumn{2}{c}{ ns } & \multicolumn{2}{c}{ ns } \\
\hline
\end{tabular}

$\mathrm{ns}=$ not significant with respect to sex, but acetabular depths were significantly different with respect to side $(\mathrm{P}<0.01$, right hip and $\mathrm{P}<0.02$, left hip).

Table 4

The prevalence of hip dysplasia in adult Malawians

\begin{tabular}{lllll}
\hline Sex & $\begin{array}{l}\text { No. of hips } \\
\text { with dysplasia }\end{array}$ & $\begin{array}{l}\text { Total No. } \\
\text { of hips }\end{array}$ & $\%$ & $P$ \\
\hline Men & 12 & 104 & 11.54 & \\
Women & 10 & 76 & 13.16 & ns \\
\hline
\end{tabular}

$\mathrm{ns}=$ not significant 
Table 5

Comparison of prevalence of hip dysplasia in men from different population groups

\begin{tabular}{|c|c|c|c|c|c|}
\hline $\begin{array}{l}\text { Population } \\
\text { Group }\end{array}$ & $\begin{array}{l}\text { Dysplasia with } \\
\text { respect to CEA(\%) }\end{array}$ & Authors & $\begin{array}{l}\text { Malawians/ } \\
\text { Nigerians }\end{array}$ & $\begin{array}{l}\text { Variations } \\
\text { Malawians/ } \\
\text { Chinese }\end{array}$ & $\begin{array}{l}\text { Nigerians/ } \\
\text { Chinese }\end{array}$ \\
\hline Malawians & 11.5 & Present study & & & \\
\hline Nigerians & 3.3 & $\begin{array}{l}\text { Gombe et al. } \\
1996\end{array}$ & $\mathrm{P}<0.001$ & $\mathrm{P}<0.05$ & $\mathrm{P}>0.5$ \\
\hline Chinese & 4.3 & $\begin{array}{l}\text { Lau et al. } \\
1995\end{array}$ & & & \\
\hline
\end{tabular}

$\mathrm{CEA}=$ Centre Edge Angle

Figure 1

Pelvic roentgenogram to illustrate the three measurements of acetubar depth, angle and the centre angle

Figure 2

Pelvic roentgenograms in women to illustrate normal hips and dysplastic ones with respect to centre edge angles (CEA)
$\mathrm{A}$ and $\mathrm{B}=$ Normal hips, $\mathrm{CEA}$ at $28^{\circ}$ and $33^{\circ}$, respectively; $\mathrm{CD}$ and $\mathrm{E}=\mathrm{Hip}$ dysplasia, $\mathrm{CEA}$ at $19^{\circ}, 20^{\circ}$ and $25^{\circ}$ (in a man) respectively.

The angles were significantly different between the sexes $(\mathrm{P}<0.001)$, but there were no significant differences between left and right hips within the same sex $(\mathrm{P}>0.5$ and $\mathrm{P}>0.1)$. Acetabular were deeper in men than in women in both hips and this was significant $(\mathrm{P}<0.01$ right hip, $\mathrm{P}<0.02$ left hip), (Table 3); but there was no significant difference between the left and right hip within the same sex. The prevalence of hip dysplasia with respect to centre-edge angle was significantly greater in Malawian men (11.54\%) as compared to Nigerians (3.30\%) (4) and Chinese men (4.5\%) (10), $(\mathrm{P}<0.001$ and $\mathrm{P}<0.05$, respectively, Table 5). Hip dysplasia with respect to centre-edge angle is illustrated in Figure 2.

\section{DISCUSSION}

This study has demonstrated variation in acetabular angles and depth between men and women, but not the centre-edge angle. The significant differences observed in acetabular depth and angles could be due to the wider pelvis of women that would appear to reduce the acetabular angle and depth. In a study of 23 radiographs of normal infants aged 1-7 days, and 20 radiographs of normal hips in children aged 11-24 months, Kleinberg and Lieberman (5) found no sex differences between them. It is possible that the changes we have observed in women most likely set in at puberty when hormonal changes occur as an adaptation to child bearing in adulthood.

The prevalence of dysplasia has been reported for the first time in Malawi (Figure 2). A comparison of the prevalence of dysplasia with respect to centre edge angles between Malawian and Nigerian men (4), demonstrated that dysplasia was significantly higher in Malawians $(11.54 \%)$ than in Nigerians $(3.30 \%)$. This emphasises regional variations in acetabular depths and centre edge angles within the African continent (7). Similarly, a comparison of the prevalence of dysplasia 
between Malawian and Chinese men (10) with respect to centre edge angle, demonstrated a significantly higher rate in Malawians (11.54\%) than in the Chinese $(4.50 \%)$.

This shows racial variations in acetabular measurements with respect to centre edge angles. It is clear therefore that differences in prevalence of dysplasia between sexes, regions and races (4 - 6) necessitate the determination of baseline geometric acetabular measurements in any population, as they tend to vary. However, the picture is not always clear-cut. It has been demonstrated for example that the prevalence of acetabular dysplasia is similar between the Chinese and British men (2), yet these are of different races. The present study has also demonstrated that the prevalence of dysplasia was higher in Malawian women (13.16\%) than men (11.54\%) (Table 4), a significant indicator of low stability of the female hip joint.

In conclusion we have determined acetabular angles and depth, we have shown sexual influences upon these parameters, and we have determined the prevalence of hip dysplasia from adult Malawians sampled. The prevalence of dysplasia was found to be greater in adult Malawian women than men, and on comparison, the prevalence of dysplasia was found to be higher in Malawian men than in Nigerian (4) and Chinese (10) men. We hope this study will assist clinicians in the region and in Malawi in particular to interpret X-ray films of the hip and to manage orthopaedic problems of the hip. Further studies are required, however, to generate more data on agespecific pelvic anthropometry and more specifically arthropometry of the hip.

\section{ACKNOWLEDGEMENTS}

To the staff of the Radiology Departments at Queen Elizabeth Central and Blantyre Adventist Hospitals.

\section{REFERENCES}

1. Moore, L. The lower limb. In: Clinically Oriented Anatomy 3rd Ed. Baltimore: Williams and Wilkins, 1992; 373

2. McCarthy, J.J., Fox, J.S. and Gurd, A.R. Innominate osteotomy in adolescents and adults who have acetabular dysplasia. J. Bone and Joint Surgery. 1996; 78:14551461.

3. Nelitz, M., Guenther, K.P., Gunkel, S. and Puhl. Reliability of radiological measurements in the assessment of hip dysplasia in adults. Brit. J. Radiology. 1999; 72:331-334.

4. Ali-Gombe, A., Croft, P.R. and Silman, A.J. Osteoarthritis of the hip and acetabular dysplasia in Nigerian men. $J$. Rheumatology. 1996; 23:512-515.

5. Kleinberg, S. and Liberman, H.S. The acetabular index in infants in relation to congenital dislocation of the hip. Arch Surgery. 1932; 32:1049-1054.

6. Stuhlberg, S.D. and Harris, W.H. Acetabular dysplasia and development of osteoarthritis in the hip. In: Proceedings of the fourth open scientific meeting of The Hip Society. St Loius: CV Moseby, 1976.

7. Igbigbi, P.S. and Kwatampora. J. Lower limb angles of East African subjects. West. Afr. J. Anat. 1997; 5:9-15.

8. Tonnis, D. Normal values of the hip joint for the evaluation of $\mathrm{X}$-rays in children and adults. Clinical Orthopaedics and Related Res. 1976; 119:39-47.

9. Unett, E.M. and Royle, A.J. Radiographic techniques and a

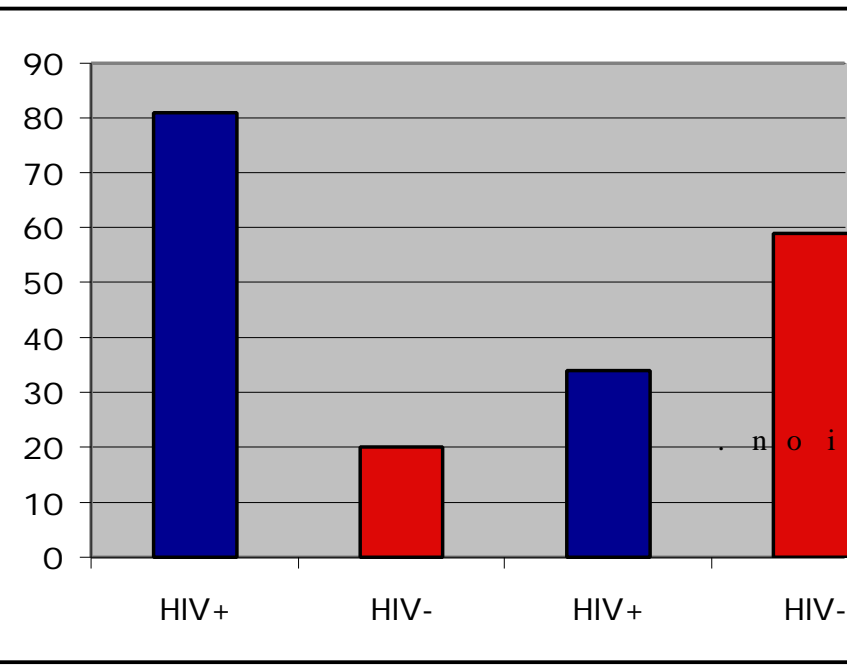

$1^{\text {st }}$ edition, London: Chapman and Hall, 1997; 92-94.

10. Lau, E.M., Lin, F., Lam, D., Silman, A. and Croft, P. Hip osteoarthiritis and dysplasia in Chinese men. Ann. Rheum. Dis., 1995, 54:965-969. 